\title{
The Driving Source Design of Differential Susceptibility Detection System Based on ATmega16
}

\author{
Liuci Zhou* and Shangkun Ren \\ Key Laboratory of Nondestructive Test \\ Education Ministry \\ Nanchang Hangkong University \\ China \\ *Corresponding author
}

\begin{abstract}
To search the ability of detect metal cracks by differential susceptibility technology, a sawtooth wave driving source system are needed. This driving source is composed of sawtooth wave generator, control unit, summator and amplifier. And solved the problem of other driving source can't output sawtooth wave whose frequency and voltage are adjustable. Compared with other driving source, this one can provide high voltage and large current, have higher noise-signal ratio, can complete satisfied to the demand of differential susceptibility detection system.
\end{abstract}

Keywords-differential susceptibility; ATmega16; driving source

\section{INTRODUCTION}

After a Long term's operation, many damages like stress concentration and fatigue damage will appear in metal component and lead to accidents ${ }^{[1-2]}$. Differential susceptibility detection is a new technology to early test and evaluate the stress concentration situation and fatigue damage degree through measure the maximal numerical value of differential susceptibility ${ }^{[3]}$.Compared with traditional measurement, this technology have high sensitiveness and reliability ${ }^{[4]}$.

The structural sketch of differential susceptibility detection system's probe sensor are showed in Figure I,when the sawtooth voltage are connected to the exciting coil, the test coil will output a relative sawtooth wave. The damage's position can be judged accurately through analyse the exciting coil's output voltage.

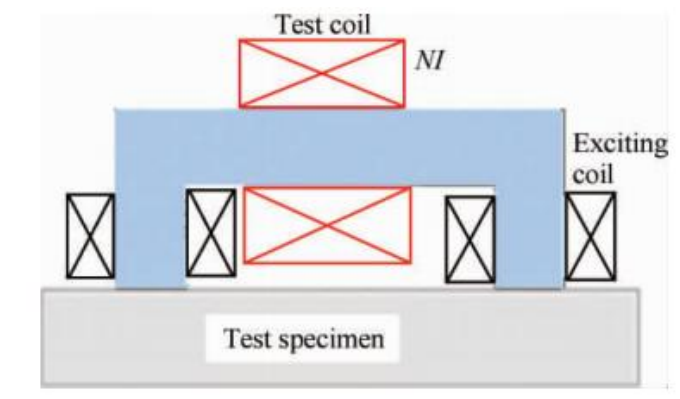

FIGURE I. STRUCTURAL SKETCH OF PROBE SENSOR

As is showed in Figure II, the driving source need to provide two kinds of wave: equal period and equal voltage. The equal period wave should output seven sawtooth waves in one cycle, every period are Ts. The first sawtooth wave's voltage is $0-2 \mathrm{~V}$, and the second is $0-4 \mathrm{~V}$...the seventh is 0 $14 \mathrm{~V}$.The equal voltage wave output seven sawtooth waves in one cycle as well, but every wave's voltage are same:0-15V, the first wave's period is Ts, the second is 2Ts...the seventh is $7 \mathrm{Ts} .1 \mathrm{~ms} \leq \mathrm{T} \leq 100 \mathrm{~ms}$.

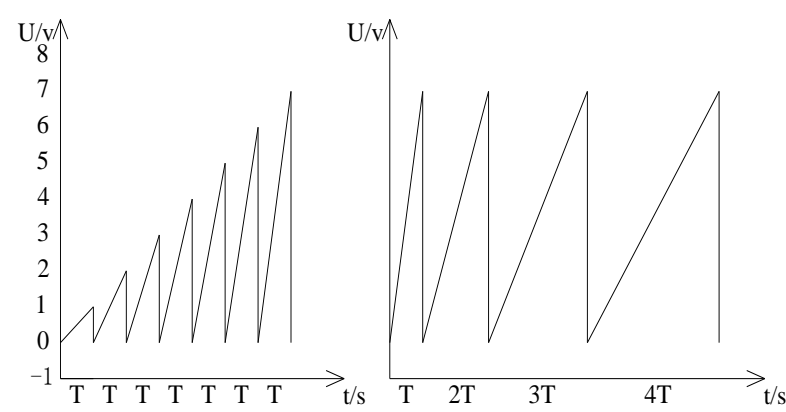

FIGURE II. STRUCTURAL SKETCH OF PROBE SENSOR

In general ways, sawtooth wave can be obtained by high speed DA converter or intergrator, in this case, DA converter's output are not continuous and contains much harmonic. The wave intergrator generated are continuous, so an intergrator are used to generate sawtooth wave in this design.

\section{The STRUCTURE OF DRIVING SOURCE CIRCUIT}

This circuit are mainly composed of four parts: sawtooth wave generator, control unit, summator and amplifier. Sawtooth wave generator is used to generate sawtooth wave whose period and voltage are adjustable; control unit is composed of MCU and digital potentiometer, and it is used to change the period and voltage of sawtooth wave; summator is used to booster the voltage of sawtooth wave above zero potential; amplifier is composed of operational and power amplifier, and used to provide high voltage and large current. The structure flowchart of the driving source circuit are showed in Figure III.

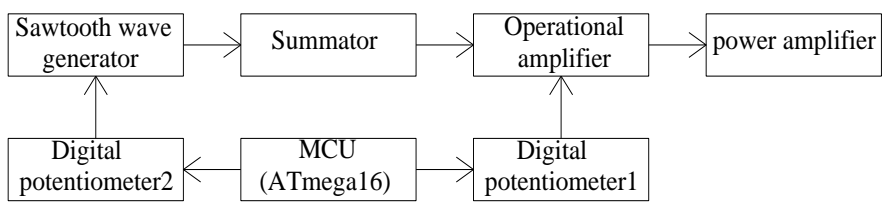

FIGURE III. THE STRUCTURE FLOWCHART OF THE DRIVING SOURCE CIRCUIT 


\section{The Generate OF SAWtooth WAVE}

Through a phase retardation comparator and a $\mathrm{RC}$ reverse integration circuit as is showed in Figure IV, a triangular wave is generated. The duty ratio can be changed through change the effective resistance of RV1. When the triangular wave's duty ratio is above $98 \%$, triangular wave will very similar to sawtooth wave.

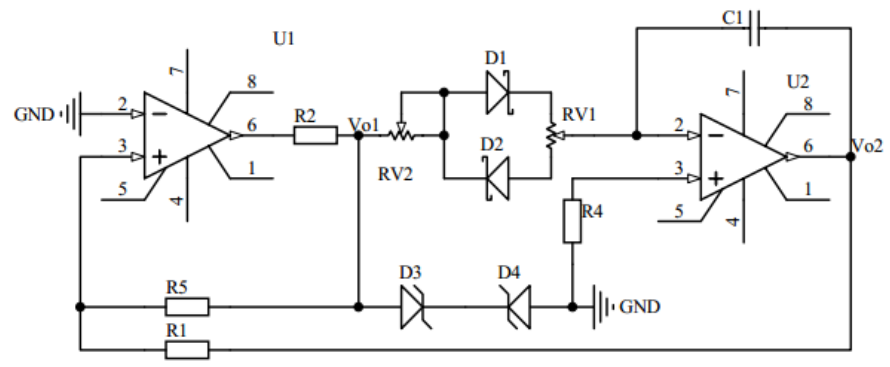

FIGURE IV. THE SCHEMATIC DIAGRAM OF SAWTOOTH WAVE GENERATOR

Vo1 will output impulse wave, and Vo2 will output sawtooth wave, the relation of Vo2's voltage and frequency with R1, R5 and C iFs showed in Eq.1.

$$
\mathrm{Vo} 2 \propto \frac{\mathrm{R}_{1}}{\mathrm{R}_{5}}, \mathrm{f} \propto \frac{\mathrm{R}_{5}}{4 \mathrm{R}_{1} \mathrm{C}}
$$

The wave of Vo1 and Vo2 is showed in Figure V.

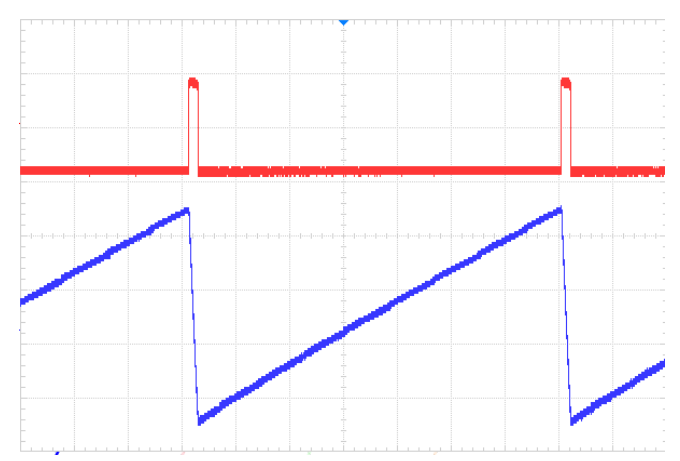

FIGURE V. THE WAVE OF VO1 AND VO2

\section{The Generate of EQual Period Sawtooth Wave}

When the circuit are set to generate equal period signal, the parameters of sawtooth wave generator will not be changed, but the parameters of operational amplifier will be changed to change Vo2's output. The operational amplifier choose OPA134 and the digital potentiometer choose X9C103, their circuit connection diagram is showed in Figure IV.

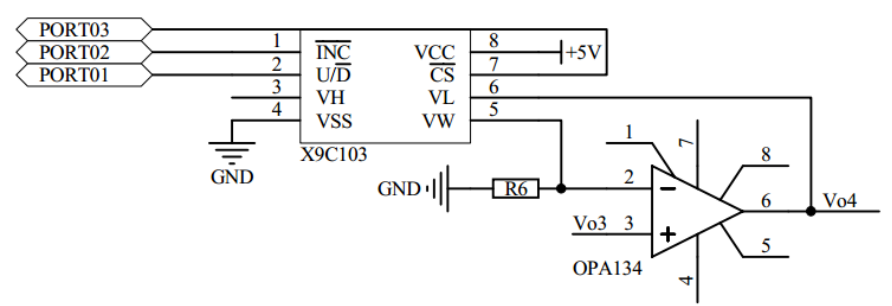

FIGURE VI. ADJUSTABLE GAIN AMPLIFIER CIRCUIT
Digital potentiometer can switch its output resistance by change the numerical value of it's internal register, And this process can only cost few microseconds.X9C103 is a 99 degrees digital potentiometer designed by Xicor company, the resistance between VW and VL is $40 \Omega-10 \mathrm{k} \Omega$, increased by $101 \Omega$ every degree[5]. In FIGURE IV, R6 $=1 \mathrm{k} \Omega$, the relation between Vo and Vi is:

$$
\mathrm{Vo} 4=\left(1+\frac{\mathrm{R}}{\mathrm{R}_{6}}\right) \mathrm{Vo} 3
$$

$\mathrm{R}$ is the resistance between VW and VL. If set CS to low, U/D to high, $\mathrm{R}$ will increase $101 \Omega$ when INC have a trailing edge. If set CS to low, U/D to low, R will decrease $101 \Omega$ when INC have a rising edge.

As is showed in Figure V, When Vo1 is high potential, Vo2 will drop, So the time to change operational amplifier's gain is when Vo1 output an impulse. Connect PORT01-03 with ATmega16's I/O pin, Vo1 with pin INT0 of ATmega16, when Vo1 output an impulse, ATmega16 will trigger an external interrupt. During this interrupt, ATmega16 change the internal register of $\mathrm{X} 9 \mathrm{C} 103$, change the numerical value of $\mathrm{R}$. During the former seven times, U/D is high and $\mathrm{R}$ will increase $\mathrm{n} \times 101 \Omega$, during the eighth time, U/D is low and $\mathrm{R}$ will decrease $n \times 101 \Omega$. n's numerical value is showed in Table I.

TABLE I. THE RELATION OF N AND OPA134'S GAIN

\begin{tabular}{|c|c|c|c|c|c|c|c|c|c|}
\hline Time & 0 & 1 & 2 & 3 & 4 & 5 & 6 & 7 & 8 \\
\hline $\mathbf{n}$ & 0 & 10 & 10 & 9 & 10 & 10 & 10 & 10 & 69 \\
\hline Gain & 1.04 & 2.05 & 3.06 & 3.97 & 4.98 & 5.99 & 6.00 & 7.01 & 1.04 \\
\hline
\end{tabular}

V. The Generate of Equal Voltage SaWtooth WaVe

Equation. 2 has showed that the sawtooth wave's period are determined by the numerical value of R1,R5 and C, any change of those parameters will change the capacitor's charge and discharge time constant, and change the sawtooth wave's period and voltage. In the generate of equal voltage sawtooth wave, another digital potentiometer will be used to replace R5.When pin INT0 of ATmega16 detect an impulse and trigger an external interrupt, the numerical value of digital potentiometer2(R5) will change, and the period of sawtooth wave will change, too.

But equation. 1 has also showed that the change of $\mathrm{R} 5$ will change Vo2's voltage, so when digital potentiometer2 changes its numerical value, digital potentiometer 1 should change its numerical value to keep sawtooth wave's output voltage as a constant.

\section{SUMMATOR}

The wave of sawtooth wave generator generated are alternating current, not direct current, so it's important to translate it. A traditional way to do this is use a summator to translate it. The circuit diagram of summator is showed in Figure VII. 


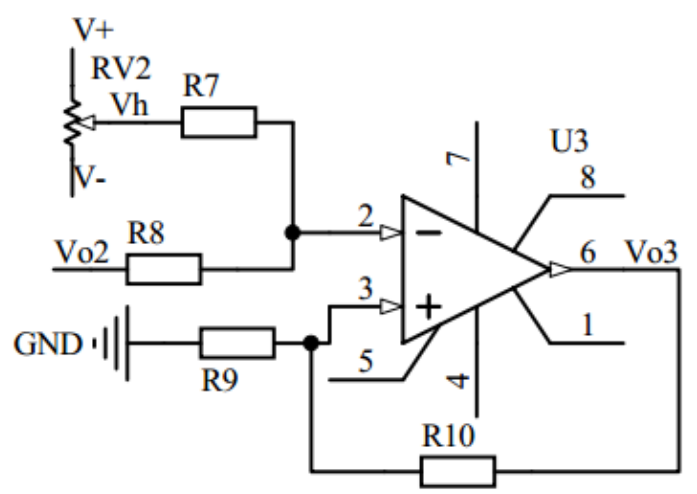

FIGURE VII. THE CIRCUIT DIAGRAM OF SUMMATOR

In Figure VII, the relation of Vo3 and Vo2 can be described as Eq.3:

$$
\mathrm{Vo} 3=\frac{\mathrm{R}_{9}+\mathrm{R}_{10}}{\mathrm{R}_{9}\left(\mathrm{R}_{7}+\mathrm{R}_{8}\right)}\left(\mathrm{V}_{\mathrm{h}} \mathrm{R}_{8}+\mathrm{Vo}_{2} \mathrm{R}_{7}\right)
$$

Set $\mathrm{R} 7=\mathrm{R} 8=\mathrm{R} 9=\mathrm{R} 10=10 \mathrm{k} \Omega$, then:

$$
\mathrm{Vo} 3=\mathrm{V}_{\mathrm{h}}+\mathrm{V}_{\mathrm{O} 2}
$$

Regulate the numerical numerical value of $\mathrm{Vh}, \mathrm{Vo} 2$ will be translated to direct current.

\section{POWER AMPLIFIER}

Power amplifier is a kind of operational amplifier which can output high voltage and large current. Compared with the wave obtained by PWM technology, power amplifier can output fewer harmonic wave.OPA549 is a kind of power amplifier designed by TI technology company. This chipcan drive inductive load, and dual supply to $30 \mathrm{~V}$, can output $8 \mathrm{~A}$ current continuously. Figure VIII is the circuit diagram of OPA549.

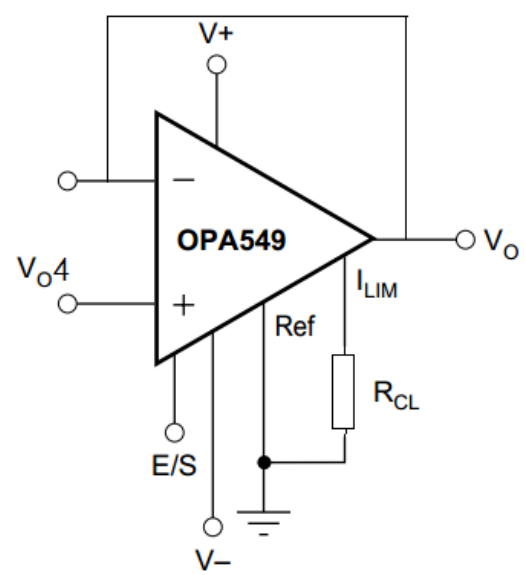

FIGURE VIII. THE CIRCUIT DIAGRAM OF OPA549

In FIGURE8, the maximum output current of OPA549 is set by $\mathrm{RCL}^{[6]}$ :

$$
\mathrm{I}_{\max }=\frac{75000}{\mathrm{R}_{\mathrm{CL}}+7500}
$$

OPA549's output can be disable by force E/S pin to low, connect pin E/S to an I/O pin of ATmega16 can control it's output.

\section{TEST RESUlt}

Connect all the modules aforesaid, set ATmega16 to generate equal period sawtooth wave, use oscilloscope to observe the output of OPA549, then connect an exciting coil as showed in Figure I, observe the voltage of OPA549;Set ATmega16 to generate equal voltage sawtooth wave, use oscilloscope to observe the output of OPA549, then connect the exciting coil, observe OPA549's output. The output of OPA549 is showed in Figure IX

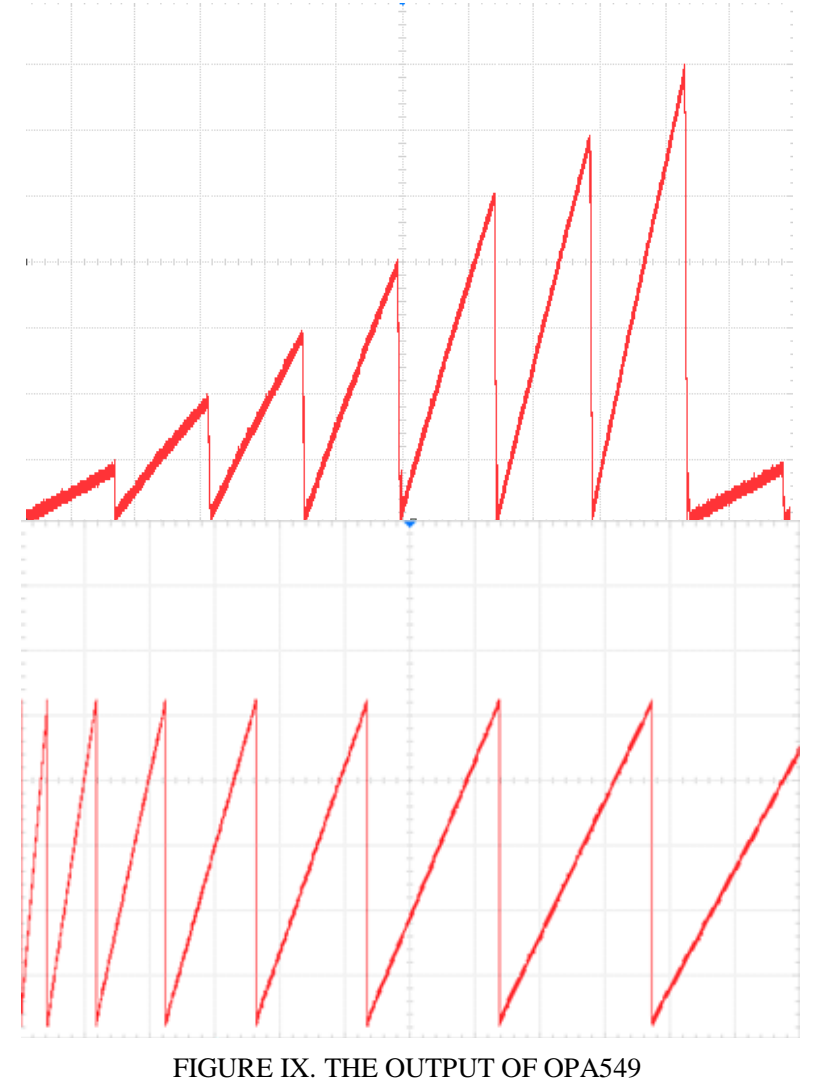

When this source works at equal period mode, the voltage it output ranges from $0-14 \mathrm{~V}$, and when it works at equal voltage mode, the voltage is $0-15.5 \mathrm{~V}$.In the mode of equal period, every wave's voltage increase progressively, and in the mode of equal voltage, every wave's period increase progressively. No matter any mode, its period can be changed by change R1 in Figure IV. By adjusting the numerical value of $\mathrm{R} 1$, each wave's period can easily changes from $1 \mathrm{~ms}$ to $100 \mathrm{~ms}$.

\section{SUMMARY}

In differential susceptibility detection system, the test coil's output are closely related to driving source, so the design of driving source is the core to this system. This design generated a kind of sawtooth wave based on intergrator and ATmega16, which can provide the highest voltage of $15 \mathrm{~V}$ for differential susceptibility detection System. 


\section{REFERENCES}

[1] HUANG $\mathrm{H}$ h,ZHANG X,LIU R J,et.Metal magnetic memory testing method and ap-plication based on GMR effect[J].Chinese Journal of Scientific Instrument,2013,34(2):241-246

[2] YANG E,LI L M,CHEN X,Magnetic field aberration induced by cycle stress[J].Journal of Magnetism and Magnetic Materials,2007,312(1):7277

[3] REN Shangkun,XU Zhenhan,Evaluating of Microstructure Damage and Strain for Ferromagnetic Specimens Based on Sensitive Differential Susceptibility. Acta Aeronautica et Astronautica Sinica[J],2014. 35 (5): $1452-1458$

[4] REN Shangkun,GUO Feng,XU Zhenhan,Studies on new testing technique and experiment of stress fatigue damage for $20 \#$ steel component[J]. Chinese Journal of Scientific Instrument,2014,35(5):1155-1160

[5] LI Bing, Development and test of the AC field detection instruments[D].NanChang Hangkong University,2013

[6] OPA549 Data Sheet.Texas Instruments.lnc,2013 